\title{
Highlights vom Nephrologie-Update
}

\section{METABOLISCHES SYNDROM}

\section{Gewichtsreduktion kommt auch den Nieren zugute}

- Bei Patienten mit metabolischem Syndrom wird häufiger eine Albuminurie gefunden. Sie ist ein Risikofaktor für kardiovaskuläre und renale Erkrankungen. Im Rahmen einer Studie mit ca. 7000 Teilnehmern wurde untersucht, ob eine Gewichtsabnahme auch die Urin-Albuminausscheidung günstig beeinflusst.

Das Ergebnis: Eine signifikante Gewichtsabnahme führte zu einem Rückgang der Albuminausscheidung im Urin um im Mittel 2,2 mg/24 Stunden, eine Gewichts- zunahme dagegen zu einem leichten Anstieg um 0,4 mg/24 Stunden. Bei jedem Vierten kam es mit der Gewichtsabnahme sogar zu einer Normalisierung der Mikroalbuminurie. Eine Progression von normaler Albuminausscheidung zur Mikroalbuminurie wurde bei $15 \%$ der Personen mit Gewichtszunahme dokumentiert. Ein normales Körpergewicht ist daher nicht nur im Hinblick auf Herz und Gehirn, sondern auch für die Nieren vorteilhaft, so Prof. Johannes Mann, München.

\section{CHRONISCHE NIERENINSUFFIZIENZ}

\section{Ist eine Eiweißrestriktion sinnvoll?}

— Die Frage, inwieweit eine eiweißarme Diät bei Patienten mit chronischer Nierenerkrankung sinnvoll ist, wird seit Jahren kontrovers diskutiert. Dafür spricht, dass eine eiweißarme Diät den Harnstoffund Phosphatspiegel senkt, die Insulinresistenz, die renale metabolische Azidose und die Osteodystrophie verbessert und die Proteinurie vermindert.

Nach einer neueren Metaanalyse wird durch eine Niedrig-Eiweißdiät auch das Risiko einer Verschlechterung der Nierenfunktion um $31 \%$ verringert. Bevor eine
Eiweißrestriktion empfohlen wird, sollte jedoch der Ernährungsstatus erfasst werden. Bei ausreichender Kalorienzufuhr empfiehlt sich, die Eiweißaufnahme auf o,6-0,8 g/kg KG/Tag zu reduzieren. Üblicherweise werden in Deutschland ca. 1,2 g/kg KG aufgenommen.

Eine Metaanalyse der vorliegenden Daten von Kindern und Jugendlichen mit chronischer Niereninsuffizienz ergab dagegen, dass eine Niedrig-Eiweißdiät bei ihnen die Progression der Niereninsuffizienz nicht beeinflussen kann.

\section{BERECHNUNG DER GLOMERULÄREN FILTRATIONSRATE}

\section{Bei älteren Frauen häufig falscher Alarm}

- Wenn die glomeruläre Filtrationsrate (GFR) nach der MDRD-Formel aus dem Kreatinin berechnet wird, besteht die Gefahr, dass zu viele ältere Personen, insbesondere Frauen, schon bei normalen Serumkreatininwerten als niereninsuffizient eingeschätzt werden.

Die MDRD-Formel wurde nämlich für Patienten mit bekannter Nierenerkrankung mit einem mittleren Serum-Kreatininwert um 2,3 mg/dl und einer mittleren GFR um $40 \mathrm{ml} / \mathrm{min}$ entwickelt. Bei einer errechneten GFR über $60 \mathrm{ml} / \mathrm{min}$ liegen die tatsächliche GFR und ein aus dem SerumKreatinin berechneter GFR-Wert zum Teil weit auseinander. Keine zuverlässigen Da- ten gibt es außerdem für über 65-Jährige. Untersuchungen bei potenziellen Lebendnierenspendern unter 65 Jahren haben gezeigt, dass die MDRD-Formel bei normalen Serum-Kreatininwerten die GFR vor allem bei Frauen unterschätzt.

Nach Meinung von Prof. Johannes Mann, München, ist die Abschätzung der GFR nach der MDRD-Formel deshalb nur bei Patienten mit bekannter Nierenerkrankung oder erhöhten Serum-Kreatininwerten sinnvoll. Dagegen dürfte die Umrechnung der Serum-Kreatininwerte besonders bei Frauen über 70 Jahren zu einer hohen Rate an falsch positiven Niereninsuffizienz-Befunden führen.

\section{KONTRASTMITTEL-GABE}

\section{Wie kann eine Nephropathie verhindert werden?}

- Die gefürchtetste Komplikation beim Einsatz von Röntgenkontrastmitteln ist das akute Nierenversagen. Besonders gefährdet sind Patienten mit vorbestehender Niereninsuffizienz. Weitere Risikofaktoren sind kardiovaskuläre Erkrankungen, hämodynamische Instabilität, nephrotoxische Pharmaka und eine Anämie.

In einer neueren Studie konnte gezeigt werden, dass zur Vermeidung einer Kontrastmittel-Nephropathie eine isotone $\mathrm{NaHCO}_{3}$-Infusion effektiver ist als eine $\mathrm{NaCl}$-Infusion.,Damit ist eine Umstellung der üblichen Präventionstherapie auf eine $\mathrm{NaHCO}_{3}$-Infusion gerechtfertigt“, so Prof. Kai-Uwe Eckardt, Nürnberg.

Die Wirksamkeit von Acetylcystein (ACC) zur Prävention einer akuten Nierenfunktionsverschlechterung ist dagegen bisher nicht eindeutig geklärt, obwohl in mehreren Studien eine positive Wirkung gezeigt wurde. Die geringen Kosten und die das sehr niedrige Nebenwirkungsrisiko rechtfertigen jedoch einen großzügigen Einsatz bei Patienten mit Risikofaktoren für eine Kontrastmittelnephropathie.

Lange Zeit wurde auch Dopamin in sog. Nierendosis verabreicht, um einer Nierenfunktionsschädigung vorzubeugen. Bisher gibt es jedoch keine Daten, die den Nutzen belegen. Während eines akuten Nierenversagens kann Dopamin die Nierenperfusion sogar verschlechtern.

Dr. med. Peter Stiefelhagen =

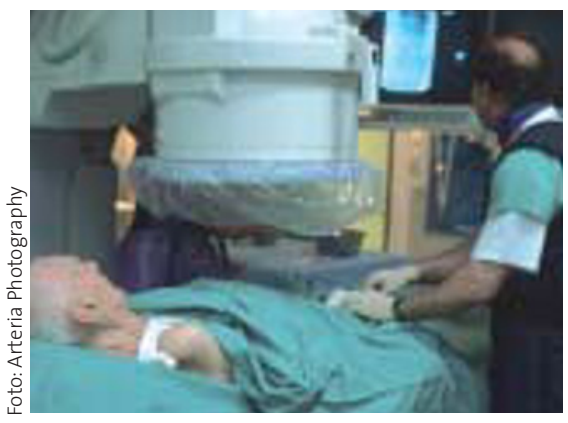

Patienten mit Niereninsuffizienz haben ein besonders hohes Risiko für eine Kontrastmittel-Nephropathie.

- Seminar Nephro Update am 30./31. Mai 2008 in Wiesbaden (Veranstalter: med update) 